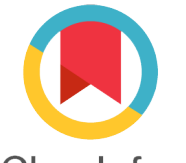

Check for updates

\title{
Erythropoietin dose and survival of hemodialysis patients
}

\author{
Mahdi Mohammadian ${ }^{1}$, Hamid Salehiniya ${ }^{2}$, Salman Khazaei ${ }^{3}$, \\ Abdollah Mohammadian-Hafshejani ${ }^{4,5}{ }^{*}$
}

\author{
${ }^{1}$ Department of Social Medicine, School of Medicine, Dezful University of Medical \\ Sciences, Dezful, Iran \\ 2Zabol University of Medical Sciences, Zabol, Iran \\ ${ }^{3}$ Department of Epidemiology, School of Public Health, Hamadan University of Medical \\ Sciences, Hamedan, Iran \\ ${ }^{4}$ Department of Epidemiology and Biostatistics, School of Health, Shahrekord University \\ of Medical Sciences, Shahrekord, Iran \\ ${ }^{5}$ Department of Epidemiology and Biostatistics, School of Public Health, Tehran \\ University of Medical Sciences, Tehran, Iran
}

\section{Keywords}

*For correspondence:

amohamadii1361@gmail.com

Competing interests: The authors declare that no competing interests exist.

Received: 16 June 2017

Accepted: 03 Jul 2017

Published: 28 Jul 2017

Copyright The Author(s) 2017. This article is published with open access by BioMedPress (BMP).

This article is distributed under the terms of the Creative Commons Attribution License (CC-BY 4.0) which permits any use, distribution, and reproduction in any medium, provided the original author(s) and the source are credited.
Erythropoietin, Survival, Hemodialysis

Chronic kidney disease (CKD) is known as a major health problem worldwide (Levey et al., 2007). The CKD is defined as a stage of disease in which the patient's kidney function is less than a half of normal capacity (2). If the kidney function is $10 \%$ to $15 \%$ less than the normal capacity, the patient has reached the End Stage Renal Disease (ESRD). At this stage, the kidney transplant or dialysis with hemodialysis or peritoneal dialysis is necessary for patient's survival (Levey et al., 2002).

The incidence of ESRD is rapidly increasing globally, so that the incidence of disease has had the ten-time increased in America during the past few years (Health and Services, 2011). On average, the number of patients, who receive hemodialysis treatment, has had the annual increase of approximately $7 \%$ (Lysaght, 2002). The prevalence of this disease varies in different parts of world. The highest incidence belongs to Taiwan with 2447 patients per one million people, but the lowest incidence belongs to the Philippines with 110 patients per one million people (Mongoh et al., 2008). 
There is a significant statistical relationship between the anemia with low survival in patients with chronic renal failure undergoing the hemodialysis (Pfeffer et al., 2009; Singh et al., 2006). In recent years, the Erythropoiesis-stimulating agent (ESA) has been widely used as a treatment for anemia in patients with chronic kidney disease (CKD) and patients with ESRD. However, the treatment of anemia results in the increased survival rates in these patients. According to the conducted clinical trial studies, the modified hemoglobin $(\mathrm{Hb})$ rate to normal range through Erythropoiesis-stimulating agent (ESAs) will not lead to the improved outcomes in these patients (Besarab et al., 1998; Drüeke et al., 2006; Pfeffer et al., 2009; Singh et al., 2006), so that the ratio of myocardial infarction, congestive heart failure, stroke, hospitalization and mortality in a group with target hemoglobin level of $13 \mathrm{~g} / \mathrm{dL}$ is higher than the target hemoglobin level of $11 \mathrm{~g} / \mathrm{dL}$ in a randomized clinical trials (Pfeffer et al., 2009). Therefore, the higher dose of Erythropoietin in patients with higher target hemoglobin level leads to an increased risk of death and non-improved life quality compared to the group with lower target levels.

According to a research by Elani Streja et al for investigating the relationship between the received dose of Erythropoietin and mortality in dialysis patients, there is a positive dose-response relationship between weekly dose of Erythropoietin drug and the risk of death. According to this study, the higher dose of Erythropoietin drug is along with increased mortality, so that compared to base group (group with weakly does of less than 6000 units), the ratio of mortality in patients with weekly doses of 6000 to less than 12,000 units is equal to $(1.0295 \% \mathrm{Cl} 0.94-1.1)$, and $(1.0895 \% \mathrm{Cl} 1-1.18)$ in group with a weekly dose of 12,000 to less than 18,000 units, and $(1.1795 \% \mathrm{Cl} 1.06-1.28)$ in group with a weekly dose of 18,000 to less than 24,000 units, and $(1.2795 \% \mathrm{Cl} 1.15-1.41)$ in group with a weekly dose of 24,000 to less than 30,000 units, and finally $(1.52$ $95 \% \mathrm{Cl} 1.37$ to 1.69 ) in group with a weekly dose of 30,000 units and higher (Streja et al., 2016). Therefore, the scientific guidelines are approved and it is suggested modifying the partial hemoglobin levels in dialysis patients by erythropoietin drug, but it is not recommended obtaining the same hemoglobin level as the healthy people's standard levels in these patients by Erythropoietin drug (Drüeke et al., 2006).

\section{Abbreviations}

CKD:Chronic kidney disease

$\mathrm{Cl}$ :Confidence Interval

ESAs: Erythropoiesis-stimulating agent

ESRD: End Stage Renal Disease 


\section{Biomedical Research \& Therapy}

ISSN: 2198-4093

www.bmrat.org

\section{References}

Besarab, A., Bolton, W.K., Browne, J.K., Egrie, J.C., Nissenson, A.R., Okamoto, D.M., Schwab, S.J., and Goodkin, D.A. (1998). The effects of normal as compared with low hematocrit values in patients with cardiac disease who are receiving hemodialysis and epoetin. New England Journal of Medicine 339, 584-590.

Drüeke, T.B., Locatelli, F., Clyne, N., Eckardt, K.-U., Macdougall, I.C., Tsakiris, D., Burger, H.-U., and Scherhag, A. (2006). Normalization of hemoglobin level in patients with chronic kidney disease and anemia. New England Journal of Medicine 355, 2071-2084.

Health, U.D.o., and Services, H. (2011). Kidney disease statistics for the United States. Bethesda, MD: National Kidney and Urologic Diseases Information Clearinghouse, National Institutes of Health.

Levey, A., Atkins, R., Coresh, J., Cohen, E., Collins, A., Eckardt, K.-U., Nahas, M., Jaber, B., Jadoul, M., and Levin, A. (2007). Chronic kidney disease as a global public health problem: approaches and initiatives-a position statement from Kidney Disease Improving Global Outcomes. Kidney international 72, 247-259.

Levey, A.S., Coresh, J., Bolton, K., Culleton, B., Harvey, K.S., Ikizler, T.A., Johnson, C.A., Kausz, A., Kimmel, P.L., and Kusek, J. (2002). K/DOQl clinical practice guidelines for chronic kidney disease: evaluation, classification, and stratification. American Journal of Kidney Diseases 39.

Lysaght, M.J. (2002). Maintenance dialysis population dynamics: current trends and long-term implications. Journal of the American Society of Nephrology 13, S37-S40.

Mongoh, M.N., Dyer, N.W., Stoltenow, C.L., and Khaitsa, M.L. (2008). Risk factors associated with anthrax outbreak in animals in North Dakota, 2005: a retrospective case-control study. Public Health Reports 123, 352-359.

Pfeffer, M.A., Burdmann, E.A., Chen, C.-Y., Cooper, M.E., de Zeeuw, D., Eckardt, K.-U., Feyzi, J.M., Ivanovich, P., Kewalramani, R., and Levey, A.S. (2009). A trial of darbepoetin alfa in type 2 diabetes and chronic kidney disease. New England Journal of Medicine 361, 2019-2032.

Singh, A.K., Szczech, L., Tang, K.L., Barnhart, H., Sapp, S., Wolfson, M., and Reddan, D. (2006). Correction of anemia with epoetin alfa in chronic kidney disease. New England Journal of Medicine 355, 2085-2098.

Streja, E., Park, J., Chan, T.-Y., Lee, J., Soohoo, M., Rhee, C.M., Arah, O.A., and KalantarZadeh, K. (2016). Erythropoietin dose and mortality in hemodialysis patients: marginal structural model to examine causality. International journal of nephrology 2016. 